\title{
Decision Support in the Process of Choosing a Residential Building Technology
}

\author{
Magdalena Gicala ${ }^{1, *}$, Joanna Sagan ${ }^{1}$, Anna Sobotka ${ }^{1 *}$ \\ ${ }^{1}$ AGH University of Science and Technology in Krakow, Poland
}

\begin{abstract}
The choice of construction technology depends on many factors, which are now increasingly determined by the developing concept of sustainability. Decisions made at the stage of building planning and design should take into account not only the technical but also environmental, social and economic efficiency of the building throughout its life cycle. The aim of the article is the development of the methodology of supporting the technology selection process on the basis of research results, experience and opinions of building users. The DSS (decision support system) developed based on this concept may facilitate potential investors selection of technologies and support designers and constructors to improve their solutions.
\end{abstract}

\section{Introduction}

Within the building construction market, investors and developers offer to construct residential buildings, especially single-family houses (being still the largest segment of the construction industry) in various construction technologies and systems. They include various raw and building materials (for example ceramics, concrete, timber, etc.), structures (for example framing, slabs, columns and slabs), construction methods (monolithic, pre-fabricated) and building equipment and machines. Additionally, type of finishing and building utility systems - very important in building use - can also be made according to different material and construction (technological) solutions. When choosing a construction technology, houses or flats purchasers usually pay attention to costs (price) and sometimes to construction process duration, however these choices (made both by a purchaser as a future user and for example a developer) more and more often consider operation costs becoming as minimal as possible in passive buildings. Alongside, the social energy-saving demand is achieved, as well as environmental protection aspects.

A comprehensive approach to assessment and choice of a construction technology, being compliant to sustainable building and covering a whole life cycle as well as a reverse supply chain, requires to consider plenty of factors/parameters and use of a multi-criteria analysis. Vast knowledge in the field of environmental impacts of building products during their production, construction processes, building use/operation (including renovations) and decommissioning (demolishing and recycling), as well as LCCA (life cycle cost analysis) assumptions are necessary too.

This social approach when choosing a product is not compulsory, it doesn't make a certain investor or user interested, though some decisions (especially during the production process) are subject to regulations. However, certain knowledge supporting the realization of sustainable building principles should be constantly developed. In foreign and Polish subject literature there are published research works result from this field and suggested recommendations (for example [2]) for choices and decisions made in certain phases of an investment building process.

Due to the multitude of analysis factors, the use of MCDA is suggested. MCDA techniques are a valuable tool for analyzing complex decision situations and are conducive to making informed decisions that are appropriate for the assumed criteria. MCDA techniques take into account the experience of experts and create evaluation systems based on values and knowledge. Many publications concern the comparison and assessment of the effectiveness of MCDA individual methods. These include for example the TOPSIS (Technique for Order of Preference by Similarity to Ideal Solution), AHP (Analytic Hierarchy Process), SAW (Simple Additive Weighting), ELECTRE (ELimination Et Choix Traduisant la REalité), and COPRAS (Complex Proportional Assessment) methods. One of the most popular is the TOPSIS method, classified as the basic modelling methods of linear ordering of multi-feature objects.

The paper includes analysis of three construction technologies of the single-family house (building shell),

\footnotetext{
* Corresponding author: mgicala@agh.edu.pl
} 
referred to user opinions obtained in pilot test surveys as well as a result of foreign experience. The holistic approach to the evaluation of construction technologies with reference to various aspects (environmental, social and economic) including each stage of building life cycle, requires to support the decision-making process with methodology proposed in this paper.

\section{The idea of the DSS decision-making system model}

Variety of product's (a material, a technology or a building) factors in life cycle assessment causes the analysis being performed to be a multi-criteria one. The evaluation made on the basis of environmental, social and economic criteria enables to choose a kind of a product, i.e., for example, a construction technology, that meets sustainable building assumptions to the largest extent. The assessment scheme, being a basis to develop the integrated method and the computer DSS (decision support system), was shown at the Fig. 1.

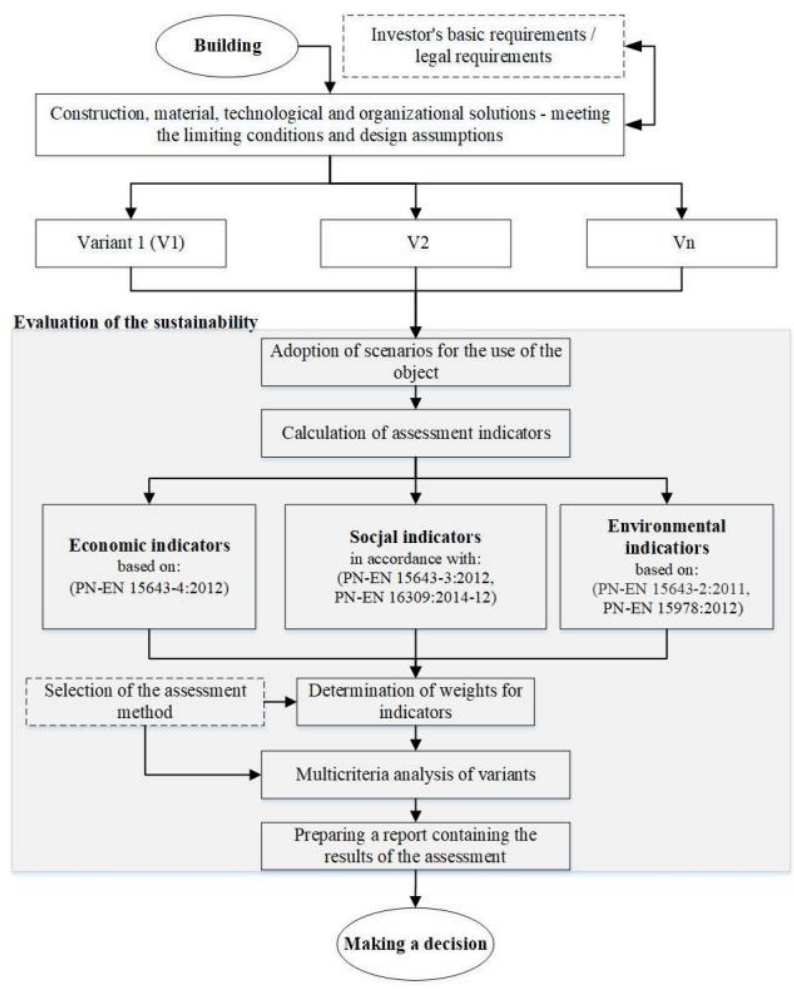

Fig. 1 Graphic interpretation of the evaluation system Source: own elaboration

The methodical basis for environmental assessment in a building life cycle can be found in the standards $[3,4]$ and many published papers, for example $[5,6]$, that supplement them. An economic analysis of building processes and facilities generally takes the form of costs and benefits calculation spreading overall life cycle stages with use of dynamical methods of economic effectiveness assessment for investment projects. General rules and requirements related to building social assessment are included in [7]. The standard specifies categories of evaluation indicators, among them particularly important for construction processes is the "loadings on the neighbourhood" category characterized by the following indicators: noise, emissions to outdoor air, soil and water as well as shocks and vibrations. The mentioned indicators have also been classified as factors harmful for health in working environment [8], thus impact of noise, dustiness and vibration is suggested to be evaluated from both employee's and bystanders' point of view.

The aforesaid standards and multiple paper works and publications can be used to calculate partial indicators and the product evaluation synthetic indicator, however, it should be noted they do not refer to all conditions affecting a final assessment result and choice of a solution.

Practical implementation of sustainability assumptions within technologies proposed by producers, designers and developers, as well as their multi-criteria assessments require to develop a multi-modal computer program/system, for example in a form of expert system's framework. It results from the vastness of information necessary to be collected (as expertise, databases) and processed, as well as the need of drawing conclusions and "providing advice" for the decision-making process.

The examples of partial assessments and their reference to global experience, as well as opinions of residential building investors/users in the case of analyzed technologies were presented in the subsequent chapters.

\section{The example of evaluation of selected technologies in subsequent stages}

\subsection{Technology assessment in the product stage}

Three residential building construction technologies were evaluated [9]. The subject of the assessment was a singlefamily residential building, one-storey located in southern Poland (Małopolskie Voivodeship), constructed in the technology of self-supporting building development systems based on foamed polystyrene (T1) with the usable area of $110.75 \mathrm{~m} 2$. Alternative material and construction solutions for the building, such as the technology of timber frame (T2) and the traditional technology with the use of ceramic building materials (T3), were considered. The analysis covered the environmental, social and economic aspects of sustainable building, represented by the set of criteria significantly determined by recommendations specified in standards $[4,7,10]$. Figure 2 presents the research results for the environmental aspect, conducted on the basis of the Ecopoint concept proposed by BRE [11]. The most environmentally advantageous technology is timber frame with the lowest Ecopoint index. 


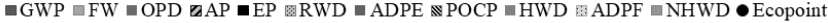

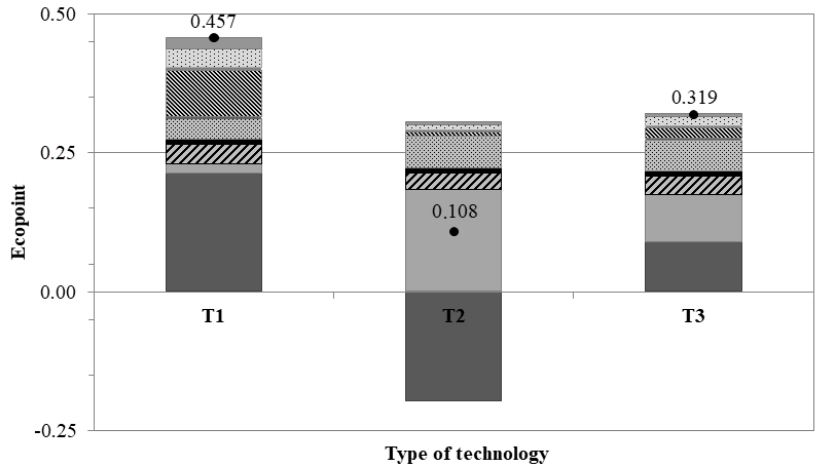

Fig. 2 The results of the environmental analysis according to the Ecopoint concept. Source: own elaboration

The following abbreviations were used: GWP - global warming potential; FW - net use of fresh water; ODP - depletion potential of the stratospheric ozone layer; AP - acidification potential of soil and water; EP - eutrophication potential; RWD - radioactive waste disposed; ADPE - abiotic depletion potential for nonfossil resources; POCP - formation potential of tropospheric ozone; HWD - hazardous waste disposed; ADPF - abiotic depletion potential for fossil resources; NHWD - non-hazardous waste disposed.

The environmental aspect was the only one analyzed with regard to several criteria. However this set of criteria do not reflect the entire group of indicators suggested by the standard, it was found by the authors as the one being especially important in creating the environmental profile because of the strong correlation between these indicators and the others. Each of other 2 aspects of sustainability was represented by 1 indicator, proving the existence of difficulties in determining criteria and carrying out the assessment that requires various limitations and is not regulated by the standard within initial stages of the building lifecycle. The multi-criteria analysis based on selected methods (tables 1 and 2) allowed not only to determine the most advantageous construction technology with reference to the given criteria, but also to classify materials as recommended, intermediary and not recommended during construction of sustainable buildings, as well as to evaluate the level of implementation of sustainability requirements in the newly developed technologies.

Table 1. The values of criteria (sustainability aspects) measures (original $-\mathrm{x}_{\mathrm{ti}}$, normalized $-\mathrm{z}_{\mathrm{ti}}$ ) and synthetic indicator (Weighted Sum Method)

\begin{tabular}{|c|c|c|c|c|c|c|c|}
\hline \multirow{2}{*}{$\mathbf{T}$} & \multicolumn{2}{|c|}{ Ep } & \multicolumn{2}{|c|}{$\mathbf{U}, \mathbf{W} / \mathbf{m}^{2} \mathbf{K}$} & \multicolumn{2}{|c|}{ Pm, PLN } & \multirow{2}{*}{ ? } \\
\hline & ? 国回 & ? 回回 & ? 回回 & ? 国国 & ? & ? 圆回 & \\
\hline T1 & 0.46 & 0.24 & 0.11 & 1.0 & 376.52 & 1.00 & 0.75 \\
\hline $\mathrm{T} 2$ & 0.11 & 1.00 & 0.21 & 0.55 & 511.56 & 0.74 & 0.76 \\
\hline $\mathrm{T} 3$ & 0.32 & 0.34 & 0.23 & 0.48 & 483.93 & 0.78 & 0.53 \\
\hline $\mathbf{W}$ & \multicolumn{2}{|c|}{$1 / 3$} & \multicolumn{2}{|c|}{$1 / 3$} & \multicolumn{2}{|c|}{$1 / 3$} & \\
\hline
\end{tabular}

The following abbreviations were used: Ep - Ecopoint value, $\mathrm{J}_{\mathrm{t}}$ - synthetic indicator, $\mathrm{Pm}$ - price of envelopes building materials per $1 \mathrm{~m}^{2}$ of usable area, $\mathrm{T}-$ technology, $\mathrm{U}$ - heat transfer coefficient of external wall, $\mathrm{W}$ - criterion weight.

Source: own elaboration.
Table 2. Distances of technologies from ideal and anti-ideal solutions (TOPSIS method)

\begin{tabular}{|c|c|c|c|}
\hline \multirow{2}{*}{ T } & \multicolumn{3}{|c|}{ Results of TOPSIS method } \\
\cline { 2 - 4 } & $\mathbf{d}_{\mathbf{t}}{ }^{+}$ & $\mathbf{d}_{\mathbf{t}}{ }^{-}$ & $\mathbf{d}_{\mathbf{t}}$ \\
\hline $\mathrm{T} 1$ & 0.20 & 0.13 & 0.40 \\
\hline $\mathrm{T} 2$ & 0.11 & 0.21 & 0.65 \\
\hline $\mathrm{T} 3$ & 0.18 & 0.08 & 0.31 \\
\hline
\end{tabular}

The following symbols are used: $d_{t}-$ relative closeness of $t^{\text {th }}$ technology to the ideal solution; $\mathrm{dt}^{+}$- distance of the $\mathrm{t}^{\text {th }}$ technology from the ideal solution; $d_{t}{ }^{-}$- distance of the $t^{\text {th }}$ technology from the anti-ideal solution, T- technology. Source: own elaboration

The results of this study can be concluded as follows: the technology of timber frame is the closest one to the optimal solution with reference to the criteria being selected. Among two other solutions, the T3 technology is more distant from the dominant one and it is assumed it does not meet sustainable building requirements on the satisfactory level.

The obtained results confirm recommendations on the selection of material-related solutions in the aspect on environmental requirements included in the guides for investors, designers and producers (for example [2]). The material-related solutions suggested by the guide authors were shown in table 3 .

Table 3. Recommendations regarding the choice of building material solutions. Source: own elaboration on the basis of [2]

\begin{tabular}{|c|c|}
\hline $\begin{array}{r}\text { Building } \\
\text { element }\end{array}$ & $\begin{array}{c}\text { Characteristic of preferred and } \\
\text { alternative solutions }\end{array}$ \\
\hline $\begin{array}{l}\text { External wall } \\
\text { construction }\end{array}$ & $\begin{array}{l}\text { The preferred solution: Priority in the } \\
\text { choice of material of the external walls of the } \\
\text { building is attributed to wood. It results from } \\
\text { the lack of negative impact on the climate of } \\
\text { processes related to the production of } \\
\text { wooden products (which are renewable). The } \\
\text { problematic issue is the use of wood } \\
\text { impregnation treatments with preparations } \\
\text { that, during the life of the building, as a } \\
\text { result of their release into the atmosphere, } \\
\text { have a harmful effect on the environment. } \\
\text { For the same reasons, it is not recommended } \\
\text { to use paints, emulsions and other means to } \\
\text { decorate or protect wood outdoors. Due to } \\
\text { many factors negatively affecting the } \\
\text { structure of the wood (including moisture, } \\
\text { UV rays, high / low temperature), weakening } \\
\text { and damaging elements, impregnation } \\
\text { treatments and periodic renovation works } \\
\text { are, however, indispensable. It is } \\
\text { recommended to use environmentally and } \\
\text { healthily safe products that do not emit } \\
\text { harmful Volatile Organic Compounds and } \\
\text { toxic substances. } \\
\text { Alternative solution: The first alternative } \\
\text { option for wood in terms of environmental } \\
\text { performance are masonry elements. The } \\
\text { processes of their products require } \\
\text { significant energy inputs and the } \\
\text { consequence of its intensive consumption is } \\
\text { not only the depletion of non-renewable } \\
\text { fuels but also increased emissions of harmful } \\
\text { substances into the atmosphere. Despite the } \\
\text { indicated adverse environmental effects, this } \\
\text { solution is the suggested basic solution, }\end{array}$ \\
\hline
\end{tabular}




\begin{tabular}{|c|c|}
\hline taking into account other aspects of \\
sustainability too. Due to the high durability \\
of bricks, small requirements in the scope of \\
ongoing maintenance, widespread use and \\
the related ease of implementation of this \\
solution as well as relatively low costs, this \\
variant is considered the preferred \\
alternative.
\end{tabular}

Thus, wood is regarded as a material with exceptionally advantageous features for the environment for years, so its application is not limited to building finishing elements, but also to structural ones. Erection of the building using the timber frame technology requires relatively lower material expenditure (when compared to other commonly used solutions), and enables the reduction of load-bearing elements thickness, resulting from the specific structure of the frame. In the aspect of environmental effectiveness, this solution is preferred, as confirmed by results of the comparative analysis presented in [9].

\subsection{Analysis of house users opinions}

The opinion of investors and current users is particularly helpful in the process of improvement of constructional, material-related and architectural solutions, as it points out current tendencies in the construction industry and highlights factors determining the choice of a selected technology. As a result of public consultations, it is thus possible to get to know and reflect actual needs as well as aspirations of the society, affecting technical and functional solutions. These solutions finally decide on living comfort level for users and a local community. The designing phase mostly shapes operational parameters of a building, thus it is crucial to know user requirements in the initial stages of building life cycle.

In order to facilitate selection of solutions on the basis of user experience, pilot surveys (in which 40 persons have taken part) being the source of opinions on the analyzed construction technologies were performed. In the survey respondents assessed technology availability (subjective assessment of availability of materials, labour, building companies realizing investments within a certain technology, popularity of a technology on the local market), adaptability (ability to rebuild a building in order to meet new service functions or adapt to changing user needs), indoor air quality (subjective assessment of room microclimate defined by temperature, humidity, need/no need of ventilation) and resistance to climate changes (building resistance to harmful, destructive influence of rain, snow, wind and low/high temperatures) in the scale from 1 to 5 . Opinions of users of buildings constructed in the T2 (15 respondents) and T3 (22 respondents) technologies were presented on spider diagrams (Fig. 3). Opinions on the T1 technology were not considered because of too fewer answers.

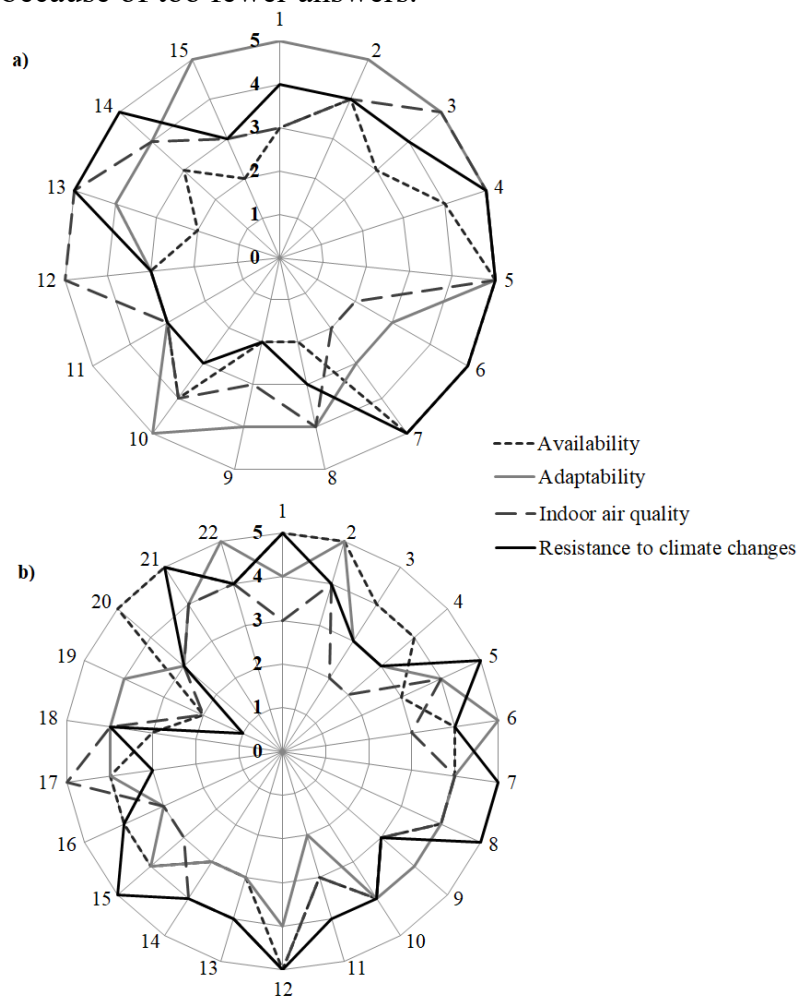

Fig. 3 Survey results: a) timber frame technology (T2), b) traditional technology using ceramic building materials (T3) Source: own elaboration

By analyzing diagram in the Fig. $3 a$ it can be confirmed that the specific structure characteristic for the timber frame technology facilitates rebuilding, modernization or adaptation and makes it possible to implement changes after completion of building works. Elimination of demolishing and masonry works reduces costs of renovations and decreases their harmful influence on users. On the other hand, availability of specialized entrepreneurship having experience in the field of 
construction of timber-framed buildings was assessed relatively poorly. Users of buildings erected in the traditional technology (T3) evaluated all analyzed aspects quite similarly (Fig. 3b). Respondents are aware of exceptionally high building resistance to weather conditions and damages caused by climatic changes. This may indicate a belief in the high durability of buildings erected in the traditional technology within a building lifecycle. Respondents' opinions on criteria significance (weights) are shown in the Fig. 4.

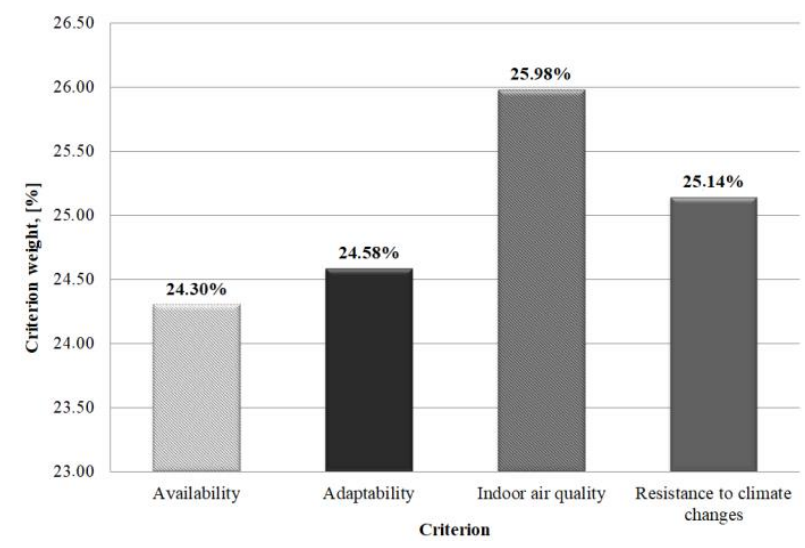

Fig. 4 Weights of factors assessed in pilot studies. Source: own elaboration

\subsection{Technology evaluation in the building end of life stage}

The period followed by the end of life stage is determined by multiple factors, for example, the durability of building materials, technical condition of a building, decision of an owner, etc. The end of life phase means demolishing a building when waste materials are generated. Building waste management is an element of effective use of assets in the construction industry and reduction of their negative impact on the environment. During all stages of building life cycle it is possible to recycle raw and building materials (Fig. 5).

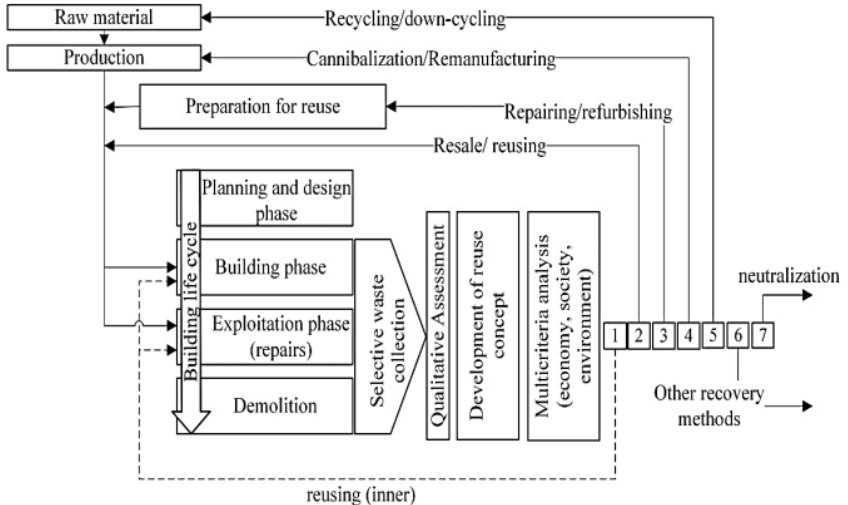

Fig. 5 Reverse logistic in the building life cycle [1]

In Poland, there are no systemic solutions referring to economical and eco-friendly waste management yet and even no list of preferred building materials that would create closed-loop supply chain within a life cycle. However, as a result of various considerations, development of waste recycling and its re-use in building and renovation of buildings is observed, as it is justified in environmental, economic and other aspects.

The analysis of assessed construction technologies for the end of life phase in the context of waste management was shown in table 4.

Table 4. Characteristic of selected material from the perspective of reverse logistics. Source: own elaboration

\begin{tabular}{|c|c|c|}
\hline $\begin{array}{c}\text { Basic technology } \\
\text { materials }\end{array}$ & $\begin{array}{c}\text { Characteristics in the } \\
\text { aspect of reverse } \\
\text { logistics (recovery) }\end{array}$ & Re-use without processing / Recycling \\
\hline \multicolumn{2}{|c|}{ Technology of self-supporting building development systems based on foamed polystyrene - T1 } \\
\hline EPS & $\begin{array}{c}\text { Crumbling of expanded } \\
\text { polystyrene } \\
\text { Dissolving of expanded } \\
\text { polystyrene }\end{array}$ & $\begin{array}{c}\text { It is possible to recover EPS and re-use it, however, due to the properties } \\
\text { of the material obtained in this way, this process is considered } \\
\text { unprofitable. In practice, recycling of expanded polystyrene and the use } \\
\text { of the obtained material as insulating backfill, soil loosener and } \\
\text { component of plasters and concretes (crumbling styrofoam), } \\
\text { waterproofing, waterproof adhesives, varnishes, wood impregnation } \\
\text { (dissolving styrofoam) are used. }\end{array}$ \\
\hline
\end{tabular}




\begin{tabular}{|c|c|c|}
\hline $\begin{array}{l}\text { AAC (autoclaved } \\
\text { aerated concrete) }\end{array}$ & Crumbling of AAC & $\begin{array}{l}\text { Reuse of AAC blocks is possible, but requires cleaning processes that } \\
\text { may result in material damage affecting the strength parameters. } \\
\text { Recycling of products through crumbling is practiced with the possibility } \\
\text { of using rubble as aggregate in the production of AAC elements. }\end{array}$ \\
\hline Metal sheet & $\begin{array}{l}\text { Dismantling the structure } \\
\text { and subjecting the } \\
\text { processing operations }\end{array}$ & $\begin{array}{l}\text { Recycling - metal recovery for steel objects is a minimum of } 80 \% \text {, saves } \\
40 \% \text { water, reduces energy consumption by } 84 \% \text { and pollutant emissions } \\
\text { by approx. } 86 \%\end{array}$ \\
\hline \multicolumn{3}{|c|}{ Technology of timber frame building $-\mathrm{T} 2$} \\
\hline Frame structure & $\begin{array}{l}\text { 1.Disassembly of the } \\
\text { structure and re-use } \\
\text { 2. Recycling }\end{array}$ & $\begin{array}{c}\text { Selection of structural elements and re-use in construction or furniture } \\
\text { industry } \\
\text { Use in the production of thermal energy }\end{array}$ \\
\hline Mineral wool & $\begin{array}{l}\text { Material collection and } \\
\text { wet crumbling }\end{array}$ & $\begin{array}{l}\text { The re-use of wool, like EPS, is considered unprofitable. } \\
\text { Wool pulp, obtained by wet crumbling, is used as an additive to plasters } \\
\text { and concretes (it is a micro-reinforcement there, eliminates cracks) }\end{array}$ \\
\hline Plasterboard & $\begin{array}{l}\text { 1. Separating products } \\
\text { from construction and re- } \\
\text { use } \\
\text { 2. Recycling }\end{array}$ & $\begin{array}{l}\text { Recovery and re-use } \\
\text { Plasterboards after processing can be used as foundation fillers for } \\
\text { terraces, fences and large concrete floors. }\end{array}$ \\
\hline \multicolumn{3}{|c|}{ Traditional technology using ceramic construction materials - T3 } \\
\hline Bricks & $\begin{array}{l}\text { 1. Material recovery } \\
\text { 2. Recycling }\end{array}$ & $\begin{array}{l}\text { Product recovery is possible. After removing the remaining mortar, the } \\
\text { blocks can be reused during the restoration of buildings or new } \\
\text { construction projects. The recovered material gives the building a unique } \\
\text { character. } \\
\text { In practice - recycling of material and use of the obtained rubble as } \\
\text { material for fillings and stabilization in infrastructure works as well as } \\
\text { aggregate constituting the basic component of concrete. }\end{array}$ \\
\hline
\end{tabular}

\section{Summary}

In the era of intensive implementation of sustainable development concept, the analysis, assessment and selection of building technologies should be holistic and take into account the simultaneous impact of environmental, social and economic aspects. The complexity of this issue requires a systemic approach and support by integrated DSS, including guidelines and algorithms for calculating partial assessments, the knowledge contained in informers, guides, etc., and dynamic changes in socio-economic conditions. The

\section{References}

1. A. Sobotka, J. Czaja, Procedia Eng. 122, 11-18 (2015)

2. D. Anink, J. Mak, C. Boonstra Handbook of Sustainable Building: An Environmental Preference Method for Selection of Materials for Use in Construction and Refurbishment (Earthscan Publications Ltd. 1996)

3. ISO 14040 Environmental management - Life cycle assessment - Principles and framework (2006)

4. EN 15643-2 Sustainability of construction works Assessment of buildings - Part 2: Framework for the assessment of environmental performance (2011)

5. O. Abbe, L. Hamilton, BRE Global Environmental Weighting for Construction Products using Selected Parameters from EN 15804 (2017), https://www.bre.co.uk/filelibrary/Materials/Environm ental-weightings-15804 final.pdf (Access: 13 Feb 2018)

6. Building Research Establishment (BRE), Green Guide to Specification Materials Industry Briefing Note $\quad 3 b$ : Normalisation (2005), developed systems supporting decision-making process are the basis for selection in its initial stages, both by the investor: the developer and the user. Moreover, they are a source of knowledge for the development of guides characterizing building materials from the point of view of sustainable building principles, facilitating the ranking of solutions based on heuristic methods and eliminating the need to conduct tedious calculations for each individual project.

http://www.bre.co.uk/greenguide/files/Normalisation BriefingDocumentFinal.pdf (Access: 26 Feb 2018).

7. EN 15643-3 Sustainability of construction works Assessment of buildings - Part 3: Framework for the assessment of social performance (2012)

8. Regulation of the Minister of Health on the testing and measurement of agents harmful to health in the work environment (2011) (in Polish)

9. M. Gicala, A. Sobotka, Sci. Rev. Eng. Environ. Sci. 26, 2(76), 159-170 (2017)

10. EN 15643-4 Sustainability of construction works Assessment of buildings - Part 4: Framework for the assessment of economic performance (2012)

11. Building Research Establishment (BRE), The Green Guide Explained BRE Centre for Sustainable Products (2015), http://www.bre.co.uk/filelibrary/greenguide/PDF/The -Green-Guide-Explained March2015.pdf (Access: 28 Feb 2018) 